\title{
Opioid prescribing habits of physicians in Kwara State, Nigeria
}

\author{
Zakari A. Suleiman ${ }^{1}$, Kolawole W. Wahab ${ }^{2}$, Israel K. Kolawole ${ }^{1}$ \\ Ghana Med J 2016; 50(2): 63-67 DOI: http://dx.doi.org/10.4314/gmj.v50i2.2 \\ ${ }^{1}$ Department of Anaesthesia, Faculty of Clinical Sciences, University of Ilorin, Ilorin, Nigeria ${ }^{2}$ Department of \\ Medicine, Faculty of Clinical Sciences, University of Ilorin, Ilorin, Nigeria
}

Corresponding author: Dr. Zakari A. Suleiman

E-mail: suzack71@yahoo.com

Conflict of interest: None declared

\section{SUMMARY}

Objective: Although opioid analgesics are effective in the treatment of moderate to severe acute, cancer and chronic non-malignant pains, they are under-prescribed in Nigeria. The objective of this study was to assess the prescription pattern of opioids among physicians in a north central State, Nigeria..

Design: This was a descriptive cross sectional study

Setting: The study was conducted at the International Association for the Study of Pain (IASP)-sponsored workshops on pain and palliative care at the University of Ilorin Teaching Hospital, Ilorin, Nigeria.

Participants: These were physicians at the monthly workshops organized by the Pain and Palliative Care Unit of the hospital between August 2011 and July, 2012.

Interventions: Pre-tested semi-structured questionnaires were used to obtain responses to questions on pain management including opioids utilization in the various hospitals of the 114 participants.

Main outcome measures: The main outcome measure was opioid prescription by the participants.

Results: Out of the 114 questionnaires distributed, 113 were returned with complete information giving a response rate of $99.1 \%$. The mean age of the respondents was $42.0 \pm 10.8$ years. Although $97.3 \%$ of the respondents reported that pain was a frequent complaint in their practice, $69.5 \%$ of those who reported seeing patients with moderate to severe pain on a daily basis rarely or never prescribed opioid analgesics. The reasons given for poor opioid prescription were fear of respiratory depression (86.8\%), fear of addiction (85.1\%) and non-availability (28.9\%).

Conclusion: Opioid prescription rate for patients with moderate-severe pain is low possibly due to myths and misconceptions about their adverse effects.

Funding: International Association for the Study of Pain (IASP) Initiative for Improving Pain Education Grant awarded to Dr. K.W. Wahab in 2011.

Keywords: Opioid analgesics, prescribing habits, physicians, Nigeria

\section{INTRODUCTION}

Opioid analgesics such as morphine, hydromorphone, oxycodone among others are recommended for moderate and severe acute, cancer and non-cancer pains based on the World Health Organization (WHO) analgesic ladder. ${ }^{1,2}$ However, the drugs are underutilized for the aforementioned conditions in Nigeria and other developing countries. ${ }^{3}$ This is in spite of the fact that there are many patients who really require this group of analgesics. With the commencement of palliative care services in few secondary and tertiary healthcare facilities in the country, the drugs are now readily available in pharmacies. However, strong opioids such as oral liquid morphine are now available; they are currently underprescribed by physicians with resultant increase in the number of unrelieved pain complaints among patients.
In a recent review of morphine prescription habits of physicians in a tertiary hospital in south western Nigeria, the two units that accounted for the highest number of prescriptions were Radiation Oncology department and Day Care Hospice Unit accounting for $51.7 \%$ and $31.8 \%$ respectively. The study observed that there was limited prescriptions from doctors in surgery and its specialities while there was no prescription from the medical wards or clinics. ${ }^{4}$ Poor awareness and fear of side effects were posited as the possible reasons for the poor prescription rate in the study. This finding however contrasts with the practice in many developed countries. 
For instance in a survey of primary care physicians in Ontario, almost all respondents reported prescribing opioids in the preceding 3 months ${ }^{5}$ which is quite different from the findings in the former study conducted in a tertiary health facility.

In view of the negative effects which uncontrolled pain may have on the quality of life of a patient, there is a need for continuous monitoring of prescription of opioid analgesics in the holistic management of patients. In this cross-sectional study, we assessed the opioid prescription practices among physicians in Kwara State, north central Nigeria.

\section{METHODS}

This was a descriptive cross sectional study of an unselected group of physicians who participated in an International Society for the Study of Pain (IASP)-sponsored monthly workshops on pain and palliative care in Kwara state, north central Nigeria from September 2011 to July 2012. All doctors who registered for the workshop were eligible to participate in the study irrespective of their professional cadre, type or location of practice. Participants were required to pre-register for the workshop and admission was on a first come first served basis with a maximum target of 45 participants per month to allow for adequate interaction between the participants and the faculty. During the period the workshop lasted, there were 226 participants with doctors constituting 176 (77.9\%). Being licensed prescribers, the doctors at the workshop were requested to respond to a pre-tested selfadministered questionnaire after informed consent was obtained. The questionnaire was based on questions that are frequently used in surveys of physicians' attitudes and practices. ${ }^{6,7}$ Information obtained included sociodemographic characteristics and location of practice. Respondents were also requested to answer questions on assessment of pain severity in patients with acute, cancer and chronic non-malignant pains, opioids availability and prescription of same at their hospitals.

\section{Data analysis}

Data obtained were analysed with the Statistical Package for the Social Sciences version 20.0 (SPSS Inc., Chic., Ill.). Descriptive analysis using frequency tables with relevant percentages for categorical variables and means and standard deviation for continuous variables were performed.

\section{RESULTS}

Out of the 176 physicians who attended the workshop, 114 consented to participate in the survey. The researchers did not assess reasons for refusal.
Anaesthetists, who regularly use strong opioids in our centre, were excluded also from this survey.

One hundred and thirteen respondents provided complete information in the returned questionnaires and formed the basis for analysis. Their ages ranged from 26 to 66 years, with a mean age of $42.0 \pm 10.8$ years; $70.8 \%$ were family physicians while males constituted $68.4 \%$ of the respondents. Only $23.9 \%$ of the respondents had at least 2 hours of lecture on pain management at undergraduate level with $39.8 \%$ reporting that they never had any lecture on pain management. These are shown in Table 1.

Table 1 Characteristics of the respondents

\begin{tabular}{|c|c|}
\hline Variable & n (\%) \\
\hline \multicolumn{2}{|l|}{ Age, years } \\
\hline Mean $\pm \mathrm{SD}$ & $42.0 \pm 10.8$ \\
\hline Range & $26.0-66.0$ \\
\hline \multicolumn{2}{|l|}{ Gender } \\
\hline Male & $77(68.1)$ \\
\hline Female & $36(31.9)$ \\
\hline \multicolumn{2}{|l|}{ Location of practice } \\
\hline Urban & $103(91.2)$ \\
\hline Sub-urban/rural & $10(8.8)$ \\
\hline \multicolumn{2}{|l|}{ Specialty } \\
\hline Family Medicine/General Practice & $80(70.8)$ \\
\hline Surgery & $8(7.1)$ \\
\hline Psychiatry & $6(5.3)$ \\
\hline Obstetrics and Gynaecology & $5(4.4)$ \\
\hline Paediatrics & $5(4.4)$ \\
\hline Ophthalmology & $3(2.7)$ \\
\hline Internal Medicine & $2(1.8)$ \\
\hline Others & $4(3.5)$ \\
\hline \multicolumn{2}{|l|}{ Duration of practice, years } \\
\hline Median & 10.0 \\
\hline Range & $1.0-39.0$ \\
\hline \multicolumn{2}{|l|}{ Duration of didactic lecture on } \\
\hline Nil & $16(14.2)$ \\
\hline$<1$ hour & $25(22.1)$ \\
\hline $\begin{array}{l}1-2 \text { hours } \\
\geq 2 \text { hours }\end{array}$ & $27(23.9)$ \\
\hline \multicolumn{2}{|l|}{ Nature of hospital service } \\
\hline Primary health care & $34(30.1)$ \\
\hline Secondary & $42(37.2)$ \\
\hline Tertiary & $37(32.7)$ \\
\hline \multicolumn{2}{|l|}{ Type of hospital practice } \\
\hline Public hospital & $77(68.1)$ \\
\hline Private Practice only & $22(19.5)$ \\
\hline Public and Private & $14(12.4)$ \\
\hline
\end{tabular}

Note: Except otherwise stated, values are frequency (percentage).

As shown in Table 2, 97.3\% of the respondents reported that pain was a frequent complaint in their practice with $52.2 \%$ reporting that they attend to patients with pain of moderate to severe intensity on a daily basis. 
Table 3 shows that $69.5 \%$ of those who attend to patients with moderate to severe pain on a daily basis rarely or never prescribed opioid analgesic for treatment of the complaint.

There was no statistically significant difference between frequency of attending to patients with moderate to severe pain and frequency of opioid prescription $\left(\mathrm{X}^{2}=\right.$ $11.75, p=0.924)$. The reasons given for poor opioid prescription by the respondents were fear of respiratory depression $(86.8 \%)$, fear of addiction (85.1\%) and nonavailability $(28.9 \%)$.

Table 2 Pain management by respondents

\begin{tabular}{ll}
\hline Variable & $\mathbf{n}(\%)$ \\
\hline $\begin{array}{l}\text { Is pain a common complaint in your } \\
\text { practice? }\end{array}$ & $110(97.3)$ \\
Yes & $1(0.9)$ \\
No & $2(1.8)$ \\
No response & \\
How often do you attend to moderate to severe \\
pain? \\
Daily \\
Weekly \\
>Weekly \\
$\begin{array}{l}\text { How often do you prescribe opioids for moder- } \\
\text { ate to severe pain? }\end{array}$ \\
$\begin{array}{l}\text { Never } \\
\text { Rarely }\end{array}$ \\
$\begin{array}{l}\text { Frequently } \\
\text { \#There were 7 non-response }\end{array}$ \\
\hline
\end{tabular}

Table 3 Relationship between frequency of attendance to moderate to severe pain and opioid prescription

\begin{tabular}{llll}
\hline $\begin{array}{l}\text { Frequency of } \\
\text { prescription }\end{array}$ & $\begin{array}{l}\text { Frequency of attendance to moderate to severe } \\
\text { pain }\end{array}$ \\
& $\begin{array}{l}\text { Daily }(\mathrm{n}=59) \\
\text { Frequently }\end{array}$ & $\begin{array}{l}\text { Weekly }(\mathrm{n}=37) \\
\text { Rarely }\end{array}$ & $>$ Weekly $(\mathrm{n}=11)$ \\
Never & $22(37.3)$ & $11(29.7)$ & $3(27.2)$ \\
\hline$X^{2}=11.75, p=0.924$ & $19(32.2)$ & $9(24.3)$ & $4(36.0))$ \\
\hline
\end{tabular}

\section{DISCUSSION}

For a rational, efficient and cost-effective pain care, assessment of drug prescribing behaviours of physicians is very important. This cross-sectional study of Nigerian physicians in the north central state of Kwara shows that pain is a common complaint in the practice of almost all the respondents. The study has also shown that only about $70 \%$ of those physicians who attend to patients with moderate to severe pain on a daily basis rarely or never prescribe opioid analgesics for treating the pain.
Whereas in the developed countries, there is an upward trend in the use of opioid analgesics over the past two decades even at primary care level ${ }^{8,9}$, this class of analgesics is still under-prescribed by physicians in Nigeria. The low opioid prescription rate in this study is similar to the findings of Nousheen et $\mathrm{al}^{10}$ in a cross sectional survey conducted in tertiary facilities in Karachi, Pakistan where they demonstrated that opioids were the least prescribed analgesics, with a prescription rate of $24.3 \%$. Studies among dental patients in Nigeria have shown an even lower prescription rate of opioids as low as $8.7 \%$. As previously reported, many practitioners tend to prescribe non-opioid analgesics especially paracetamol (acetaminophen) and non-steroidal anti-inflammatory drugs (NSAIDs) despite the fact that majority of patients experience pain of severe intensity. ${ }^{12,13}$

The respondents gave various reasons, including fear of respiratory depression, addiction and non-availability for their poor opioid prescription for moderate to severe pain. However, in view of the fact that about 4 out of every 10 respondents never had any form of didactic lecture on pain and only $23.9 \%$ of the respondents had more than 2 hours of lecture at undergraduate level there was high possibility of incorrect pain assessment by such respondents and these might have contributed to the observed low prescription rate in this study.

Given the central position that opioids occupy in the management of acute post-operative and cancer-related pain, it is imperative to promote strategies that will have great potentials of ensuring safe and appropriate opioid prescription in our environment. This step is necessary to reverse the current reluctance of physicians to prescribe opioids on the premise of over-rated adverse effects. Findings from a survey ${ }^{14}$ in the US among resident doctors show that practitioners were discouraged from prescribing opioids as a result of concerns about emerging evidence of serious public health harms from the drugs. The respondents in our study gave possible development of such adverse effects like respiratory depression and addiction as reasons for poor prescription of opioid but these are unfounded going by the pharmacology of the drugs. Misconceptions and unfounded safety concerns have been adduced for underprescriptions and suboptimal dosing of opioids. ${ }^{13}$

Contrary to the attitudes of physicians in the third world, physicians in the developed countries are very confident at prescribing opioids. In one survey, ${ }^{5}$ almost all the physicians admitted to have prescribed opioids within the preceding 3 months (95.4\%) and $75.1 \%$ and $86.4 \%$ of the respondents respectively indicated strong level of comforts for prescribing opioids for pain and confidence in their clinical skills in prescribing opioids. 
This contrasts sharply with the opioids prescription rate in our environment due to high level of misconceptions on their safety. Among others, two factors that might have accounted for the differential findings in the opioid prescription rates by practitioners between the two studies are better knowledge due to regular participation in educational activities and free access to resources on safe opioid prescriptions. Periodic educational activities on safe use of opioids can bridge the current knowledge gap and positively influence the opioid prescribing habits of physicians in our environment. A similar interventional study has demonstrated that education on managing opioid prescribing and opioid addiction enhanced physicians' confidence and comfort in opioid prescribing. ${ }^{14-16}$

The limitations of our study include the small sample size and the fact that although the participants were unselected, it is possible that most of the respondents could be those who already appreciated that they had a knowledge gap in pain management and hence were ready to participate in the monthly workshop where they were recruited from. This could have affected their responses to the questions asked. Furthermore, this study failed to address an important unexplored question: why will physicians refuse to participate in a survey on opioid prescribing pattern? This can cause significant bias in our findings because if this question was answered, the results might be different. However, in view of the similarity of the outcomes of our study with previous findings in this country and some other developing countries, we believe that our findings could still be a fair reflection of the current status as regards opioid prescription among physicians in the country. Therefore, efforts should be made to continually improve the knowledge of physicians in pain management in order to improve on the low prescribing rate and thus improve the quality of life of patients experiencing pain.

\section{CONCLUSION}

Opioid prescription rate for patients with moderatesevere pain is low possibly due to exaggerated concerns and myths and misconceptions about the adverse effects of the drugs. Periodic continuous medical education on pain management, including use of opioids, would be useful in improving on the observed poor prescription rate and thus improve management of our patients. Incorporation of pain education at undergraduate level during clinical years in the medical school can also lead to an improvement in the current poor prescription pattern and thus improved analgesia.

\section{REFERENCES}

1. World Health Organization. Cancer Pain relief. Geneva: WHO Office of Publications; 1986

2. Burton AW, Hamid H. Current challenges in cancer pain management: does the WHO ladder still have relevance? Expert Rev. Anticancer Ther. 2007; 7(11): 1501-1502.

3. http://www.incb.org/documents/Publications/Annu alReports/AR2015/English/Supplement-

AR15_availability_English.pdf

4. Elumelu TN, Abdus Salam AA, Adenipekun AA, Soyanwo OA. Pattern of morphine prescription by doctors in a Nigeriatertiary hospital. Niger J Clin Pract 2012;15:27-29.

5. Wenghofer EF, Wilson L, Kahan M, Sheehan C, Srivastava A, Rubin A et al. Survey of Ontario primary care physicians' experiences with opioid prescribing. Can Fam Physician 2011; 57: 324-332.

6. Dobscha SK, Corson K, Flores JK, Tansill EC, Gerrity MS. Veteran's affairs primary care clinicians' attitudes towards chronic pain and correlates of opioid prescribing rates. Pain Med 2008; 9(5):564-571.

7. Nwokeji ED, Rascati KL, Brown CM, Eisenberg A. Influences of attitudes on family physicians' willingness to prescribe long-acting opioids analgesics for patients with chronic nonmalignant pain. ClinTher 2007; 29(suppl): 2589-2602

8. Zin CS, Chen LC, Knaggs RD. Changes in trends and pattern of strong opioid prescribing in primary care. Eur J Pain. 2014 Oct;18(9):1343-1351.

9. Manchikanti L, Helm S 2nd, Fellows B, Janata JW, Pampati V, Grider JS, et al. Opioid epidemic in the United States. Pain Physician. 2012 Jul;15(3 Suppl):ES9-38.

10. Nousheen A, Muhammed HS, Rabia B. Analgesic prescribing in developing countries. Jordan J Pharmaceutical Sci. 2010;3(2): 137-144.

11. Azodo CC, Unoh AO. Analgesics prescription in Nigerian healthcare services. Niger J Basic Clin Sci 2013; 10: 86-90

12. Ehigiator O, Odai CD, Obuekwe ON, Azodo CC. Evaluation of drug prescriptions in oral surgery. Nig Hosp Pract 2011; 7: 77-81

13. Gbenga OO, Olabisi AA. Prevalence and pattern of pain presentation among patients attending a tertiary dental center in a southern region of Nigeria. $J$ Dent Res Clin Dent Prospect 2010; 4:42-46.

14. Roth CS, BurgessDJ. Changing residents' beliefs and concerns about treating chronic pain with opioids: evaluation of a pilot workshop. Pain Med 2008; 9(7): 890-892. 
15. Midmer D, Kahan M, Marlow B. Effects of a distance learning program on physicians' opioid-and benzodiazepine-prescribing skills. $J$ Contin Edu Health Prof 2006; 26(4): 294-301. $\diamond \mathbf{x}$ Morley-Foster PK, Clark AJ, Speechley M, Moulin DE. Attitudes toward opioid use for chronic pain: a Canadian physician survey. Pain Res Manag 2003; 8(4): 189-194 